\title{
Modulation of Aroma and Sensory Properties of Prokupac Wines by a Bacillus-based Preparation Applied to Grapes Prior to Harvest
}

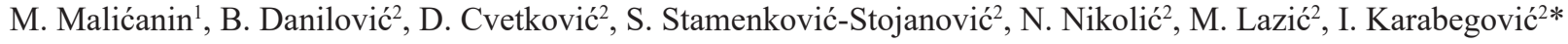 \\ (1) Faculty of Agriculture, University of Nis, Kosančićeva 4, 37000 Kruševac, Serbia \\ (2) Faculty of Technology, University of Nis, Bulevar Oslobodjenja 124, 16000 Leskovac, Serbia
}

Submitted for publication: April 2020

Accepted for publication: July 2020

Keywords: Bacillus subtilis, HS-SPME-GC-MS, aroma profile, sensory characteristics, Prokupac

\begin{abstract}
Modern viticulture requires the replacement of hazardous agrochemicals with eco-friendly, bio-based products such as microbial preparations that enhance grape and wine quality while protecting the grapevine from pest and disease attacks. This study investigated the effects of a commercially available Bacillusbased preparation on the volatile and sensory properties of wines made from Vitis vinifera, cv. Prokupac grapes. Three different concentrations of preparation based on Bacillus subtilis $\mathrm{Ch}-13$ were applied to grapevines two weeks prior to harvest. The total soluble solids in the grapes was affected by the application of $B$. subtilis $\mathrm{Ch}-1$ and the alcohol content of the wine made from these grapes was greater. Wines made from the $B$. subtilis $\mathrm{Ch}$-13-treated grapes showed an average increase in total phenolic compounds of about $\mathbf{2 7 \%}$, compared to the wine made from the untreated control grapes. The colour intensity of wines from the treated grapes, independently of the concentration, was higher by more than $\mathbf{3 0} \%$ than for the wine from the control grape sample. The $\boldsymbol{B}$. subtilis $\mathbf{C h}-13$ treatment also affected the content of 3-methyl-1-butanol, ethyl decanoate and ethyl octanoate in the wine, at about $35 \%, 40 \%$ and $20 \%$, respectively. The latter compounds are responsible for floral and fruity aromas. Generally, wines made from the treated grapes showed similar sensorial characteristics but scored better overall than the control. Principal component analysis showed a clear differentiation between wine made from the control and that from the $B$. subtilis $\mathrm{Ch}$-13-treated grapes. The results suggest that the application of $B$. subtilis $\mathrm{Ch}-13$ to grapevines two weeks prior to harvest has a positive effect on wine quality.
\end{abstract}

\section{INTRODUCTION}

Traditional agricultural practices are based on the use of large quantities of different agrochemicals (fertilisers, fungicides, pesticides, hormones), which lead to pest, weed and disease resistance, the accumulation of hazardous residues in food and a negative impact on the environment. Consequently, there is an increasing interest in modern agriculture to replace hazardous substances with alternative yet innovative practices using natural, eco-friendly and biobased preparations (Alori \& Babalola, 2018; Damalas \& Koutroubas, 2018; Abbey et al., 2019). Bearing in mind that healthy and high-quality grapes are one of the cornerstones of wine production, finding alternative techniques to control diseases in viticulture is also increasingly gaining importance.

One of the prospective solutions that meet these global demands is to replace agrochemicals with microbialbased preparations. Microbial-based preparations consist of different beneficial microorganisms that have both phytostimulatory and biopesticidal effects. Such a method is concurrently harmless to the environment, human health or the agro-ecosystem (Pertot et al., 2017), without a negative influence on the grape and wine microbiota (EscribanoViana et al., 2018). Microbial-based preparations can be applied during the preharvest period harmlessly when the grapes are highly susceptible to fungal diseases (Otoguro \& Suzuki, 2018). Using beneficial microorganisms in microbial products should not only prevent or protect grapevines from diseases and pests (Kim \& Hwang, 2007), but it can also help to enhance aroma and polyphenol compound biosynthesis, increase anthocyanin content in the berry skin (Otoguro \& Suzuki, 2018), add or mobilise nutrients from the soil (Alori \& Babalola, 2018) and improve the growth and yield of grapevines (Rolli et al., 2017). So, besides reducing the economic losses in vineyards, the application of microbialbased preparations also improves grape berry quality and positively affects wine quality (Otoguro \& Suzuki, 2018).

Different microorganisms (fungi, bacteria, yeast, actinomycetes) or their active ingredients have been used for the formulation of some commercially available microbial preparations (Abbey et al., 2019; Calvo-Garrido et al., 2019).

*Corresponding author: E-mail address: ivana.karabegovic@tt.ni.ac.rs

Acknowledgements: This research study was conducted in the Faculty of Technology at the University of Niš in Leskovac and supported by the Ministry of Education, Science and Technological Development of the Republic of Serbia (Scientific Research Funding Programme No. 451-03-68/2020-14/200133) 
Among them, Bacillus spp. have been used in many in vitro and field studies, and its antagonistic efficacy against various plant pathogens has been confirmed (Shafi et al., 2017; Calvo-Garrido et al., 2019). Aside from their antifungal effect, Bacillus spp. act as a plant growth promoter. It has been proven that this bacterium has the potential to stimulate the synthesis of grape polyphenols, aroma compounds and precursors, improve anthocyanin accumulation (Otoguro \& Suzuki, 2018) and synthesise antimicrobial secondary metabolites and fungal cell wall-degradation enzymes (Shafi et al., 2017; Alori \& Babalola, 2018; Stamenković et al., 2018). Although it is clear that using this species in viticulture opens up new possibilities for the safe production of quality grapes, and therefore wine with enhanced flavour and aroma, the exact impact that a particular microorganism might have has not been studied sufficiently.

For this reason, the aim of this study was to investigate the effect of commercial Bacillus-based preparations on grape and wine quality, as well as on the aroma and sensory profile of wines produced from an indigenous Serbian Vitis vinifera red grape cultivar, Prokupac.

\section{MATERIALS AND METHODS \\ Grape treatment}

The experiments were carried out during the 2018 season in a six-year-old vineyard (Central Serbia wine region, Tri Morave wine subregion, $43^{\circ} 37^{\prime} \mathrm{N}, 21^{\circ} 34^{\prime} \mathrm{E}$, single Royat cordon vine training system) planted with Vitis vinifera (cv. Prokupac), which is a Serbian autochthonous red grape variety. Two weeks before the grapes reached full technological maturity, a commercially available preparation based on Bacillus subtilis Ch-13 (Ekstrasol ${ }^{\circledR}$, minimum 107 $\mathrm{CFU} / \mathrm{ml}$, BioGenesis d.o.o., Serbia) was applied. Three different volume percent concentrations (v/v), 0.3\% (1.35 L/ ha), $0.5 \%(2.25 \mathrm{~L} / \mathrm{ha})$ and $0.7 \%(3.15 \mathrm{~L} / \mathrm{ha})$ (chosen according to the manufacturer's recommendations), were applied directly onto vine leaves using a hand-held compressed-air sprayer. Each treatment was performed in triplicate (three consecutive rows of approximately 100 vines for each experiment, one row per replicate). Three rows of untreated grapevines served as controls.

\section{Winemaking processes}

Grapes from each row were harvested manually (when total soluble solids reached approximately 20 to $21^{\circ}$ Brix) and further processed separately (de-stemming, crushing with the addition of potassium metabisulphite $(50 \mathrm{mg} / \mathrm{L})$ and enzyme EXV (3 g/hL, Lallemand, Canada). Yeast nutrient Fermaid E (Lallemand, Canada) was added later during fermentation $(30 \mathrm{~g} / \mathrm{hL})$. Musts were inoculated with Saccharomyces cerevisiae strain ICV D254 (25 g/hL, Lallemand, Canada) and small-scale fermentation $(50 \mathrm{~L})$ on skins was performed at $18^{\circ} \mathrm{C}$ to $20^{\circ} \mathrm{C}$ for all the samples. In order to improve maceration, the cap (solid grape parts) was punched down every three hours $24 \mathrm{~h}$ after yeast inoculation and during the active fermentation phase. Delastage (rack-and-return of fermenting juice) was performed daily until the sugar content dropped below $7^{\circ}$ Brix. When alcoholic fermentation was finished (residual sugar level under $4 \mathrm{~g} / \mathrm{L}$ ), wine samples were separated from the skins, pressed gently and sulphited
(25 mg/L), and then racked off from the primary yeast lees after $72 \mathrm{~h}$. Before bottling, wine samples were again racked off and filtered using Seitz filter plates K 100 (Pall Seitz, Germany). Finally, twelve wines were produced (triplicate of the three treatments and control) and stored in bottles for six months at $15^{\circ} \mathrm{C}$ until chemical and sensory analysis.

\section{Standard oenological parameters}

Official methods recommended by the International Organisation of Vine and Wine (OIV, 2019) were used to analyse the standard oenological parameters of wine samples. The total phenol index (TPI) was evaluated by measuring absorbance at $280 \mathrm{~nm}$ (González-Rodríguez et al., 2002), while total anthocyanins, flavonoids and flavan-3-ols were determined by the methods described by Nedelkovski et al. (2017).

\section{Extraction of volatile organic compounds in wines by headspace-solid phase microextraction (HS-SPME)}

The SPME manual holder and fused silica fibre coated with Carboxen ${ }^{\circledR} /$ Polydimetilsiloxane (CAR/PDMS) stationary phase (85 $\mu \mathrm{m}$ thickness) were used for aroma compound extraction. The fibre was preconditioned before the first use $\left(1 \mathrm{~h}\right.$ at $\left.300^{\circ} \mathrm{C}\right)$. Twenty millilitres of wine sample, $3 \mathrm{~g}$ of $\mathrm{NaCl}$ and a magnetic stirrer bar were placed in a $30 \mathrm{ml}$ amber glass bottle, closed with a rubber septum and sealed with parafilm. The samples were heated to $55^{\circ} \mathrm{C}$ and agitated using a magnetic stirrer for 15 minutes (pre-extraction). The volatiles were extracted for 35 minutes maintaining the same heating and stirring conditions. The fibre was than desorbed for 10 minutes in split/splitless inlet set at $250^{\circ} \mathrm{C}$ in $20: 1 \mathrm{split}$ mode and analysed by GC/MS and GC/FID.

Volatile organic compounds from the wine samples were analysed using an Agilent Technologies 7890B gas chromatograph, coupled with inert, selective 5977A mass detector. Components were separated using a HP-5MS column (30 m $\times 0.25 \mathrm{~mm}, 0.25 \mu \mathrm{m}$ film thickness; Agilent Technologies, USA). Helium was used as the carrier gas at a constant flow rate of $1 \mathrm{~mL} / \mathrm{min}$. The $\mathrm{GC}$ oven temperature was held for $2 \mathrm{~min}$ at $40^{\circ} \mathrm{C}$, increased to $250^{\circ} \mathrm{C}$ at a rate of $7^{\circ} \mathrm{C} /$ $\mathrm{min}$, and finally held at $250^{\circ} \mathrm{C}$ for $2 \mathrm{~min}$. The temperatures of the MSD transfer line, ion source and quadruple mass analyser were set at $300^{\circ} \mathrm{C}, 230^{\circ} \mathrm{C}$ and $150^{\circ} \mathrm{C}$, respectively. The ionisation voltage was $70 \mathrm{eV}$ and mass detection was done in the scan mode, in $m / z$ range from 25 to 550. GCFID analysis was performed under the same experimental conditions. The FID detector temperature was set at $300^{\circ} \mathrm{C}$.

Data processing was performed using MSD ChemStation (revision F.01.00.1903) in combination with AMDIS (revision 2.70) and NIST MS Search (version 2.0g) software (Agilent Technologies, USA). The retention indices of the components were determined experimentally using a homologous series of $n$-alkanes from $\mathrm{C}_{8}$ to $\mathrm{C}_{20}$ as standards, and the identification of the compounds was done using the Adams 2007 as well as Willey 6, NIST11 and RTLPEST 3 libraries. The content $(\%)$ of a particular component in the samples was determined on the basis of the area percent report generated by Agilent ChemStation software. The Area \% report gives the area of each peak as a percentage of the total area of all peaks. 


\section{Sensory analysis}

Descriptive sensory analysis was conducted by the officially certified members of the sensory panel authorised for wine sensory analysis by the Serbian Ministry of Agriculture, Forestry and Water Management (six females and five males, from 29 to 51 years old). The wine samples were evaluated in duplicate in random order, while the intensity of each attribute was rated by using a 10-point scale $(0-$ not detected, $10-$ very intense). For each wine sample, the panellists evaluated olfactory (spice, colour intensity, vegetable, red fruit berries, black fruit berries, floral, complexity, intensity, typicality and toasted) and taste (harmony, acidity, astringency, fulness, complexity, duration, structure, intensity, typicality) attributes.

\section{Statistical analysis}

Results from the standard oenological parameters of wine were analysed using one-way analysis of variance (ANOVA), followed by Tukey's HSD post-hoc test (significance $\mathrm{p}<0.05$ ). Principal component analysis (PCA) was used to determine the contribution of identified volatile organic compounds to the differences observed between wine samples. PCA was performed using Statistica 10 Software (StatSoft Inc., Tulsa, U.S.A., trial version).

\section{RESULTS AND DISCUSSION}

\section{Basic must and wine parameters}

The initial quality parameters of the must made from the control grape samples and grape samples treated with different concentrations of $B$. subtilis Ch-13 preparation are shown in Table 1. An increase in the total soluble solids of about $8 \%$ was observed independently in the preparation concentration, without a statistically significant effect on the juice $\mathrm{pH}$. Total acidity (g/L tartaric acid) was slightly different and ranged from 5.7 for the control grape to 6.2 for the musts from the treated grapes.

It is well known that sugar accumulation in grapes depends primarily on the cultivar, stage of maturity and environmental conditions (temperature, light, humidity) (Jackson, 2008; Jordão et al., 2015), but some authors indicate that viticultural practices (defoliation, cluster thinning, irrigation) could also affect the sugar content in grape berries (Esteban et al., 2002; Bogicevic et al., 2015), as well as fungal and bacterial infections (Jordão et al., 2015). Sivčev et al. (2005) confirm that the application of a biological preparation based on the Azotobacter chroococcum and Bacillus megaterium strain on the Riesling grape variety also positively affects sugar and acid accumulation in the grape juice. More recently, Escribano-Viana et al. (2018) reported that a biofungicide based on the Bacillus subtilis QST 713 had no significant impact on the $\mathrm{pH}$, sugar and acid content of Tempranillo grapes, while Chebotar et al. (2009) showed that the Bacillus subtilis $\mathrm{Ch}-13$ strain has the ability to stimulate plant growth and act as biofungicide due to the extracellular synthesis of phytohormone, lytic enzymes and other antifungal metabolites.

Although the increase in the sugar content of grapes is undesirable in the context of warmer ripening periods and a changing climate (Mozell \& Thachn, 2014), it could be useful for northern and cool-climate regions or for some varieties in which an insufficient sugar level is a common occurrence in the grapes (Yadav et al., 2011). The increase in grape sugar and acid levels in our experiments caused by the use of B. subtilis Ch-13 preparations should be considered a positive phenomenon, since the grape variety Prokupac is known to produce only satisfactory (not high) sugar levels and shows a rapid decrease in acid concentration in the final stages of ripening. The work of Marković et al. (2017), which included twenty-five different Prokupac clones, showed that only five of them reached s sugar level above $20 \%$ at the time of technological maturity. Bearing in mind that the optimal sugar content for the production of red wine is $21 \%$ to $24 \%$, it can be considered that the use of the B. subtilis Ch-13based preparation has a positive effect on the quality of the Prokupac grape and potentially has an effect on wine quality.

The effects of the application of the B. subtilis Ch-13 preparation on the basic quality parameters of Prokupac wine samples are summarised in Table 2. The application of the B. subtilis Ch-13 preparation significantly affected the quality parameters of Prokupac wines (Table 2). The wines obtained from the Prokupac grapes treated with different concentrations of this biopreparation had a higher alcohol content than the wine obtained from the untreated (control) grapes, which is in accordance with the initial sugar content of the grapes. Better grape sugar accumulation, and consequently higher wine alcohol content, was also observed in Riesling wine when grapes were treated with a microbiological preparation based on the $A$. chroococcum and B. megaterium bacterial cultures (Sivčev et al., 2005), and in Merlot wines obtained from grapes treated with a preparation based on cultures of A. chroococcum, B. megaterium and Bacillus circulans (Raicevic et al., 2004).

Wine samples obtained from grapes treated with different concentrations of $B$. subtilis $\mathrm{Ch}-13$ preparation contained a

TABLE 1

Quality parameters of control grapes and grapes treated with different concentration of $B$. subtilis preparation

\begin{tabular}{lcccc}
\hline & & \multicolumn{2}{c}{ Concentration of B. subtilis preparation, \% } \\
\cline { 3 - 5 } Parameter & Control & 0.3 & 0.5 & 0.7 \\
\hline Total soluble solids, ${ }^{\circ}$ Brix & $19.8 \pm 0.2 \mathrm{a}$ & $21.13 \pm 0.4 \mathrm{~b}$ & $21.57 \pm 0.2 \mathrm{~b}$ & $21.36 \pm 0.3 \mathrm{~b}$ \\
Total acidity, g/L tartaric acid & $5.7 \pm 0.2 \mathrm{a}$ & $5.8 \pm 0.1 \mathrm{a}$ & $5.9 \pm 0.2 \mathrm{ab}$ & $6.2 \pm 0.2 \mathrm{~b}$ \\
$\mathrm{pH}$ & $3.25 \pm 0.01 \mathrm{a}$ & $3.23 \pm 0.01 \mathrm{a}$ & $3.22 \pm 0.01 \mathrm{a}$ & $3.22 \pm 0.01 \mathrm{a}$ \\
\hline
\end{tabular}

Means followed by the same letter within a row are not significantly different at $p \leq 0.05$ by Tukey's HSD test 
TABLE 2

Quality parameters of wines obtained from control grapes and grapes treated with different concentrations of $B$. subtilis Ch-13 preparation

\begin{tabular}{lcccc}
\hline & & \multicolumn{2}{c}{ Concentration of B. subtilis preparation, \% } \\
\cline { 3 - 5 } Parameter & Control & 0.3 & 0.5 & 0.7 \\
\hline Alcohol, $\%$ & $11.5 \pm 0.01 \mathrm{a}$ & $12.3 \pm 0.00 \mathrm{~b}$ & $12.7 \pm 0.02 \mathrm{c}$ & $12.6 \pm 0.05 \mathrm{~d}$ \\
Total dry extract, g/L & $25.9 \pm 0.44 \mathrm{a}$ & $27.6 \pm 0.20 \mathrm{~b}$ & $27.4 \pm 0.40 \mathrm{~b}$ & $27.1 \pm 0.19 \mathrm{~b}$ \\
Total titratable acidity (as tartaric acid), g/L & $5.5 \pm 0.20 \mathrm{a}$ & $5.7 \pm 0.10 \mathrm{ab}$ & $5.7 \pm 0.10 \mathrm{ab}$ & $6.0 \pm 0.20 \mathrm{~b}$ \\
Volatile acids (as acetic acid), g/L & $0.50 \pm 0.09 \mathrm{a}$ & $0.32 \pm 0.05 \mathrm{~b}$ & $0.36 \pm 0.03 \mathrm{~b}$ & $0.33 \pm 0.05 \mathrm{~b}$ \\
Residual sugars, g/L & $2.0 \pm 0.22 \mathrm{a}$ & $1.5 \pm 0.09 \mathrm{~b}$ & $1.6 \pm 0.09 \mathrm{~b}$ & $1.8 \pm 0.07 \mathrm{a}$ \\
Total polyphenols, g/L & $1.23 \pm 0.07 \mathrm{a}$ & $1.39 \pm 0.04 \mathrm{~b}$ & $1.39 \pm 0.02 \mathrm{~b}$ & $1.38 \pm 0.02 \mathrm{~b}$ \\
Total anthocyanins, g/L & $0.34 \pm 0.01 \mathrm{a}$ & $0.40 \pm 0.03 \mathrm{~b}$ & $0.41 \pm 0.04 \mathrm{~b}$ & $0.39 \pm 0.01 \mathrm{~b}$ \\
Colour intensity & $0.44 \pm 0.002 \mathrm{a}$ & $0.60 \pm 0.03 \mathrm{~b}$ & $0.62 \pm 0.01 \mathrm{~b}$ & $0.54 \pm 0.04 \mathrm{c}$ \\
Wine hue & $0.568 \pm 0.04 \mathrm{a}$ & $0.511 \pm 0.04 \mathrm{~b}$ & $0.500 \pm 0.02 \mathrm{~b}$ & $0.501 \pm 0.02 \mathrm{~b}$ \\
Flavan-3-ols, mg/mL & $0.26 \pm 0.02 \mathrm{a}$ & $0.30 \pm 0.02 \mathrm{ac}$ & $0.30 \pm 0.01 \mathrm{ac}$ & $0.33 \pm 0.03 \mathrm{bc}$ \\
Total flavonoids, $\mathrm{mg} / \mathrm{mL}$ & $0.68 \pm 0.02 \mathrm{a}$ & $0.81 \pm 0.01 \mathrm{~b}$ & $0.87 \pm 0.02 \mathrm{c}$ & $0.81 \pm 0.01 \mathrm{~b}$ \\
Total phenolic index & $27.6 \pm 0.25 \mathrm{a}$ & $34.7 \pm 0.24 \mathrm{~b}$ & $36.4 \pm 0.19 \mathrm{~b}$ & $34.7 \pm 0.67 \mathrm{~b}$ \\
Free $\mathrm{SO}_{2}, \mathrm{mg} / \mathrm{L}$ & $24.76 \pm 1.08 \mathrm{a}$ & $24.74 \pm 1.14 \mathrm{a}$ & $24.04 \pm 0.86 \mathrm{a}$ & $23.68 \pm 0.92 \mathrm{a}$ \\
Total $\mathrm{SO}_{2}, \mathrm{mg} / \mathrm{L}$ & $51.96 \pm 1.16 \mathrm{a}$ & $53.92 \pm 0.96 \mathrm{a}$ & $53.58 \pm 1.06 \mathrm{a}$ & $52.90 \pm 0.98 \mathrm{a}$ \\
\hline
\end{tabular}

Means followed by the same letter within a row are not significantly different at $p \leq 0.05$ by Tukey's HSD test

higher content of total phenolic compounds, anthocyanins, flavonoids and flavan-3-ols, at about 13\%,18\%,22\% and $19 \%$, respectively when compared to the control wine sample. A statistically significant difference was observed between the control wine and wines from treated grapes $(p<0.05)$. The total phenolic index (TPI) values for wine samples from treated grapes indicate that treatment with $B$. subtilis $\mathrm{Ch}-$ 13 preparation causes an average increase in total phenolic compounds of about $27 \%$. The TPI value gives a reliable estimation of wine polyphenolic content and is considered better and more useful than other routine spectrophotometric methods for the quick and easy screening of wine quality (González-Rodríguez et al., 2002).

Recently published results show that the content of total phenolic compounds (323.2 $\mathrm{mg} / \mathrm{L}$ and $307.2 \mathrm{mg} / \mathrm{L}$ ) in Prokupac wine (2013 and 2014 vintages) was four times lower (Lakićević et al., 2019) than the contents in the wine samples analysed in this study, while a significantly higher content of total phenolic compounds (about $2.3 \mathrm{~g} / \mathrm{L}$ ) and lower levels of total anthocyanins (about $0.28 \mathrm{~g} / \mathrm{L}$ ) were observed in another sample of Prokupac wine (Malićanin et al., 2017). Such a large difference can be explained by differences in climatic factors, soil type, sunlight exposure, vineyard altitude or vinification process, which are all crucial for the wine phenolic content (Cosme et al., 2017).

Since wine phenolic compounds are extracted mainly from grape berry skins, our results indicate that the treatment with $B$. subtilis Ch-13 preparation improves the synthesis of phenolic compounds in grape berry skins, with a moderate impact on soluble solids. Therefore, it can be concluded that Bacillus treatment could enable simultaneous technological and phenolic maturation. Such a feature might facilitate the decision on the harvest date and enhance the polyphenol composition of the corresponding wines. Knowing that polyphenolic compounds strongly affect wine quality, mainly by contributing to its sensory (colour, astringency, bitter, aroma) or ageing characteristics (Niculescu et al., 2018), a higher content of these classes of compounds in wine made from treated grapes is also consistent with the fact previously reported in the literature that biopreparates based on microorganisms could improve grape and wine quality (Otoguro \& Suzuki, 2018).

More recently, it was revealed that the application of Bacillus cereus strain NRKT improves the synthesis of stilbene synthase, which is the most important enzyme for resveratrol synthesis, and consequently leads to an increase in resveratrol in the grape berry (Aoki et al., 2017). Also, our results are in line with the findings according to which sugars such as glucose, fructose and sucrose serve as signalling molecules affecting the flavonoid pathway and promoting anthocyanin synthesis (Zheng et al., 2009; Shi et al., 2018). It is safe to assume that the observed higher sugar content in treated grapes enhances the polyphenolic content in grapes and in the produced wines.

Although the content of polyphenolic compounds in grapes is considered to be dependent mainly on the grape cultivar and environmental and climatic conditions (Guerrero et al., 2019), it is worth noting that viticultural practices, such as the application of microbiological preparations, could promote the accumulation of these classes of compounds.

Treatment with $B$. subtilis Ch-13 preparation had no statistically significant effect on the free and total $\mathrm{SO}_{2}$ content 
in the wine samples, while a significant reduction in volatile acids was observed compared with the control sample(Table2). Although the amount of volatile acid detected in all samples is in accordance with European legislation $(1.2 \mathrm{~g} / \mathrm{L}$ of acetic acid), high concentrations are undesirable and would give an unpleasant aroma of acetic acid to wine (Vilela et al., 2013). Comparing the effect of three microbiological preparations based on different microorganism strains (A. chroococcum; mixture of $A$. chroococcum and $B$. megaterium or mixture of $A$. chroococcum, B. megaterium and B. circulans) on the total acids in Riesling wines, the authors highlighted that the total acid content depended on the type of microorganisms on which the preparation was based. The highest total acids $(8.21 \mathrm{~g} / \mathrm{L})$ were observed in wine from grapes treated with preparations based on $A$. chroococcum; lowest total acids $(6.32 \mathrm{~g} / \mathrm{L})$ were found in wines from grapes treated with preparations based on $A$. chroococcum and B. megaterium, while the control wine sample contain $6.45 \mathrm{~g} / \mathrm{L}$ total acids (Sivčev et al., 2005).

The residual sugar in the wine samples did not exceed $2 \mathrm{~g} / \mathrm{L}$, which indicates that, regardless of the treatment, all wines should be considered dry. The chromatic parameters of the wine samples (colour intensity, hue) indicated that the $B$. subtilis Ch-13 preparation treatment significantly affects the colour of Prokupac wine samples. The colour intensity of wines from the treated grapes, independently of the concentration, was higher by more than $30 \%$ than for the wine from the control grape sample. Colour hue represents the ratio between the yellow/orange and the red wine pigments (Coradini et al., 2014), so the higher values for the control wine sample indicate a smaller percentage of red pigments. The correlation between values for the colour intensity and the hue of wine colour, where higher colour intensity corresponds to a lower hue value, was also observed for Merlot, Vranac, Prokupac, Cabernet Sauvignon, Game (Babincev et al., 2016), Pinot Noir and Burgund (Coradini et al., 2014) wines. As the anthocyanins are mainly responsible for red wine colour, the values for the chromatic parameters were expected and in accordance with the improved accumulation of this class of compounds in the treated grape samples (Table 2). Since the wine colour is an important wine characteristic that highly affects overall consumer acceptance, and bearing in mind that wines produced from the Prokupac grape variety typically have a lower colour intensity than red wines produced from varietals such as Cabernet Sauvignon, Vranac, Merlot and Game (Babincev et al., 2016), these research findings can be considered very valuable, especially in the production of quality wines from poorly coloured grape varieties.

The content of total dry extract in all wine samples was within the range of 25 to $30 \mathrm{~g} / \mathrm{L}$, which is typical for lightbodied red wines (Castilhos et al., 2013), such as Prokupac wines are traditionally. However, significant differences were observed in total dry extract between the control sample and the wine samples produced from treated grapes, with the control wine sample having the lowest content. The alcohol content and total dry extract observed in this study were significantly higher compared with the results obtained in previous studies (Lakićević et al., 2018, 2019), in which alcohol content and total dry extract for Prokupac wine (vintage 2013 and 2014) were in the ranges $10.26 \%$ to $10.49 \%$ and $16.10 \mathrm{~g} / \mathrm{L}$ to $17.45 \mathrm{~g} / \mathrm{L}$, respectively. This may be related to the weather conditions during the growing season, different vinification procedures or yeasts, as well as the initial quality of the grape and must. A positive effect on total dry extract content has also been reported for Riesling wine obtained from grapes treated with the microbiological preparation based on $A$. chroococcum $+B$. megaterium compared to the wine obtained from the control sample (Sivčev et al., 2005). Moreover, a recent study demonstrated that treating the plant with microbial fertilisers can enhance the content of macro- and microelements in different grape varieties (Tangolar et al., 2019). Knowing that the total dry extract depends directly on the content of minerals in the grapes and wine, it can be assumed that the use of $B$. subtilis Ch-13 preparation improves the uptake of macronutrients and micronutrients and positively affects the mineral content in the treated grapes and produced wine.

However, it is also important to emphasise that the application of a microbial preparation based on B. subtilis QST713 had no significant impact on the berry and wine microbiota (Escribano-Viana et al., 2018), thus it does not affect spontaneous alcoholic fermentation.

\section{Volatile composition of wine samples}

A total of 26 different volatile aroma compounds were identified by HS-SPME-GC-MS in Prokupac wines obtained from a control and from grapes treated with different concentrations of $B$. subtilis $\mathrm{Ch}-13$ preparation. All compounds were subdivided, according to their chemical structure, into five groups (alcohols, ethyl esters, acetates, volatile fatty acids, aldehydes), among which the most abundant were higher alcohols, followed by the ethyl esters (Table 3).

The majority of the wine higher alcohols are the byproducts of alcoholic fermentation, while some could be found in the grapes (Jackson, 2008; Pineau et al., 2009). At an optimal concentration, they contribute positively to fruity characters and the complexity of wine (Lambrechts \& Pretorius, 2000). The dominating compound in the Prokupac wines analysed in our study, independently of the grape treatment, was 3-methyl-1-butanol (isoamyl alcohol), while treatments of the grapes with $B$. subtilis Ch-13 preparations increased the content of this compound in wines by about $35 \%$ compared to the control sample. It has been reported that isoamyl alcohol has a positive effect on wine aroma (Bleve et al., 2016), while other researchers have associated the presence of this compound with vegetal/pepper (Dela-Fuente-Blanco et al., 2016), herbaceous, fruity, alcohol or cheese odour characteristics (Chambers IV \& Koppel, 2013). However, although the effect of the B. subtilis Ch13 preparation treatments on the aromatic profiles of the resulting wine is not negligible, there is no clear relationship between preparation concentration and the content of wine volatile organic compounds.

Ethyl octanoate (range $13.8 \%$ to $17.8 \%$ ) and ethyl decanoate (range $5.9 \%$ to $8.5 \%$ ) were detected as the dominating esters in Prokupac wines. Generally, the application of the B. subtilis $\mathrm{Ch}-13$ preparation positively affected the presence of esters in wines. In particular, the 
TABLE 3

Identified volatile organic compounds ${ }^{\mathrm{a}}$ and their relative peak areas ${ }^{\mathrm{b}}$ (in \%) in Prokupac wine analysed by HS-SPME-GC-MS

\begin{tabular}{|c|c|c|c|c|c|}
\hline \multirow[b]{3}{*}{ Compound } & \multicolumn{4}{|c|}{ Wine sample } & \multirow[b]{3}{*}{ Aroma descriptor } \\
\hline & \multirow[b]{2}{*}{ Control } & \multicolumn{3}{|c|}{ Concentration of B. subtilis $\mathrm{Ch}-13$ preparation, $\%$} & \\
\hline & & 0.3 & 0.5 & 0.7 & \\
\hline \multicolumn{6}{|l|}{ Alcohols } \\
\hline Isobutyl alcohol & 3.2 & 1.1 & 2.6 & - & Alcohol, solvent ${ }^{1}$ \\
\hline 3-Methyl-1-butanol & 22.9 & 31 & 31.4 & 30.4 & Floral, malt, sweet ${ }^{1}$ \\
\hline 2-Methyl-1-butanol & 14.2 & 11.5 & 9.6 & 10.9 & Floral, fruity, sweet ${ }^{3}$ \\
\hline 1-Pentanol & 10.3 & 12.4 & 11.8 & 12.7 & Fruity, balsamic ${ }^{2}$ \\
\hline (S)-2-Methyl-1-butanol & 3.3 & 3.5 & 3.2 & 1.4 & - \\
\hline 1-Hexanol & 1.8 & 0.6 & 0.6 & 0.6 & Herbaceous, woody ${ }^{2}$ \\
\hline 2-Methyl-1-pentanol & 1.4 & - & - & - & - \\
\hline 2-Phenylethanol & 2.7 & 3 & 3.1 & 4.1 & Rose, honey $^{2}$ \\
\hline 4-Methyl-1-pentanol & - & 0.9 & 0.5 & 0.8 & Almond, toasted ${ }^{2}$ \\
\hline 2-Butanol & - & - & 2.1 & - & Sweet, fruty ${ }^{2}$ \\
\hline Total area $(\%)$ & 59.8 & 64 & 64.9 & 60.9 & \\
\hline \multicolumn{6}{|l|}{ Acetates } \\
\hline 2-Phenyl acetate & 1.1 & - & - & - & Rose, honey ${ }^{1}$ \\
\hline 2-Methylbutyl acetate & - & 0.3 & 0.1 & 0.3 & - \\
\hline 3-Methylbutyl acetate & - & - & - & 0.4 & Banana, apple, estery ${ }^{1}$ \\
\hline Ethyl acetate & 4.2 & 1 & 1.5 & 1.1 & Sweet, fruity ${ }^{2}$ \\
\hline Total area $(\%)$ & 5.3 & 1.3 & 1.6 & 1.8 & \\
\hline \multicolumn{6}{|l|}{ Esters } \\
\hline Ethyl butanoate & 0.2 & - & 0.1 & - & Strawberry, apple ${ }^{2}$ \\
\hline Ethyl hexanoate & 1.1 & 0.8 & 0.7 & 1.1 & Apple, fruity, sweetish ${ }^{1}$ \\
\hline Ethyl 3-methyl pentanoate & 2.2 & 2.8 & 2.7 & 3.1 & - \\
\hline Ethyl octanoate & 13.8 & 15.3 & 16.7 & 17.8 & Sweet, fruity, pear ${ }^{2}$ \\
\hline Ethyl-(4E)-decanoate & 0.6 & 0.6 & 0.9 & 1.1 & - \\
\hline Ethyl decanoate & 5.9 & 8.4 & 8.5 & 9.4 & Fruity, grape ${ }^{2}$ \\
\hline Ethyl dodecanoate & 0.5 & 0.8 & 0.8 & 0.8 & Sweet, floral, fruity ${ }^{3}$ \\
\hline Diethyl succinate & - & 0.4 & 0.5 & 0.6 & Fruity $^{2}$ \\
\hline Total area $(\%)$ & 24.3 & 29.1 & 30.9 & 33.9 & \\
\hline Volatile fatty acids & & & 1.3 & 1.5 & \\
\hline Octanoic acid & 1.6 & 1.4 & 0.3 & 0.2 & Cheese, fatty acid, sweet ${ }^{1}$ \\
\hline Decanoic acid & - & 0.3 & - & 0.6 & Fatty, unpleasant ${ }^{2}$ \\
\hline Hexanoic acid & - & - & & & Cheese, fatty acid ${ }^{2}$ \\
\hline Total area (\%) & 1.6 & 1.7 & 1.6 & 2.3 & \\
\hline \multicolumn{6}{|l|}{ Aldehydes } \\
\hline Benzaldehyde & 0.9 & 0.2 & 0.3 & 0.3 & Almond, cherry ${ }^{3}$ \\
\hline Total area (\%) & 0.9 & 0.2 & 0.3 & 0.3 & \\
\hline
\end{tabular}

1. Vilanova et al. (2010); 2. Welke et al. (2014); 3. Yilmaztekin (2014)

${ }^{\text {a }}$ Compounds identified by matching to the NIST MS library spectra and comparison of the Kovats retention indices

${ }^{\mathrm{b}}$ Relative amounts of compounds (in \%) were calculated by dividing the peak area of each component by the total peak area of all components 
content of ethyl decanoate increased greatly (by about 40\%) with an increase in preparation concentration, while the content of ethyl octanoate increased in wines from treated grapes (by about 20\%), independent of the preparation concentration. The two esters designated as most abundant in the produced Prokupac wines have been characterised previously as responsible for the dominant red-berry and fresh-fruit aromas of Merlot and Cabernet Sauvignon wines (Pineau et al., 2009) and as aroma-enhancing compounds (Zhu et al., 2016). Since fresh fruity aromas are generally desirable for red wines, these results may be of interest to red wine producers, not just when making wine from the Prokupac grape variety, but also from other grape varieties. The low level of free fatty acids should be associated with their esterification in the presence of alcohol during fermentation. Confirmation of this fact may be the existence of all corresponding ethyl esters, which are derived from the present free fatty acids.

Although wine volatile aroma compounds are mainly secondary yeast metabolites, their concentration depends directly on the chemical components of the grapes (Lambrechts \& Pretorius, 2000; McKay \& Buica, 2020). Based on the results presented, we can hypothesise that the application of $B$. subtilis Ch-13 preparation to the Prokupac grapevine increases the content of the neutral grape compounds (sugars, amino acids), which are the precursors for the formation of higher alcohols or esters and therefore can be considered responsible for the improvement in the aromatic profile of the wines.

\section{Sensory profile of wine samples}

Olfactory and gustatory characteristics, apart from the chemical composition and aromatic profile, represent one of the most essential attributes of the wine that contribute to consumer acceptance. The results of the sensory evaluation (Fig. 1) indicate that treatment by a B. subtilis Ch-13 preparation exhibits an influence on the sensory characteristics of the produced wines. All wine samples from the treated grapes, independent of the applied concentration, show similar sensorial characteristics and scored better overall results than the wine produced from the control grape sample. However, the difference is more noticeable in the gustatory than in the olfactory sensations. In fact, the wine produced from the control grape sample had the lowest value for all analysed olfactory characteristics, while for the difference was most observable for "harmony", "fulness", "complexity", "duration" and "colour intensity". This observation is supported by and based on the observed differences in basic chemical characteristics, such as the higher content of total dry extract and polyphenolic compounds (total phenolic compounds, flavonoids, anthocyanins, flavan-3-ols), the lower content of acids, and the different chromatic parameters of wines produced from the treated grapes. The impact of different viticultural practices on the sensory characteristics of wine was revealed previously (Biarnès et al., 2009; Thiollet-Scholtus et al., 2014), while wine produced from organically grown grapes compared to wine from conventionally grown grapes also demonstrated a change in taste (sour and bitter) and astringency sensations (Pagliarini et al., 2013).

Wines produced from the Prokupac grapes in this study had the highest intensity of 'red fruit berries', followed by 'black fruit berries' flavour. In terms of spice attributes, white pepper and cinnamon flavours were the most common descriptors, while linden, acacia and rose flavours were recognised as the floral attributes in all wine samples. Besides the minimal differences in 'red fruit', colour intensity and 'astringency' attributes, wines obtained from Prokupac in this study are sensorily similar to recently published results on wines from the same grape variety (Malićanin et al., 2017).

\section{Principal component analysis (PCA)}

Principal component analysis (PCA) was used to obtain additional information about the effects of the treatment by $B$. subtilis $\mathrm{Ch}-13$ preparations on the aromatic profile of the

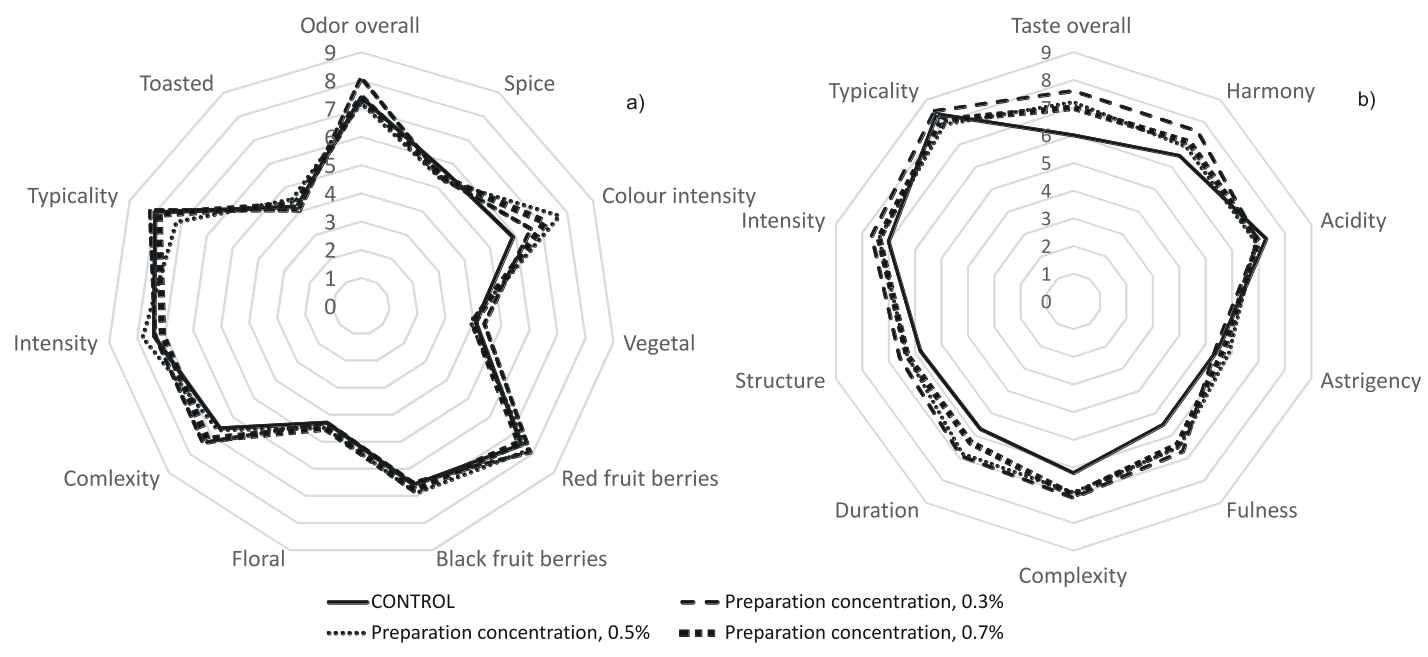

FIGURE 1

Visual appearance, olfactory (a) and gustatory (b) characteristics of Prokupac wines obtained from control grapes and grapes treated with different concentration of $B$. subtilis $\mathrm{Ch}-13$ preparation 

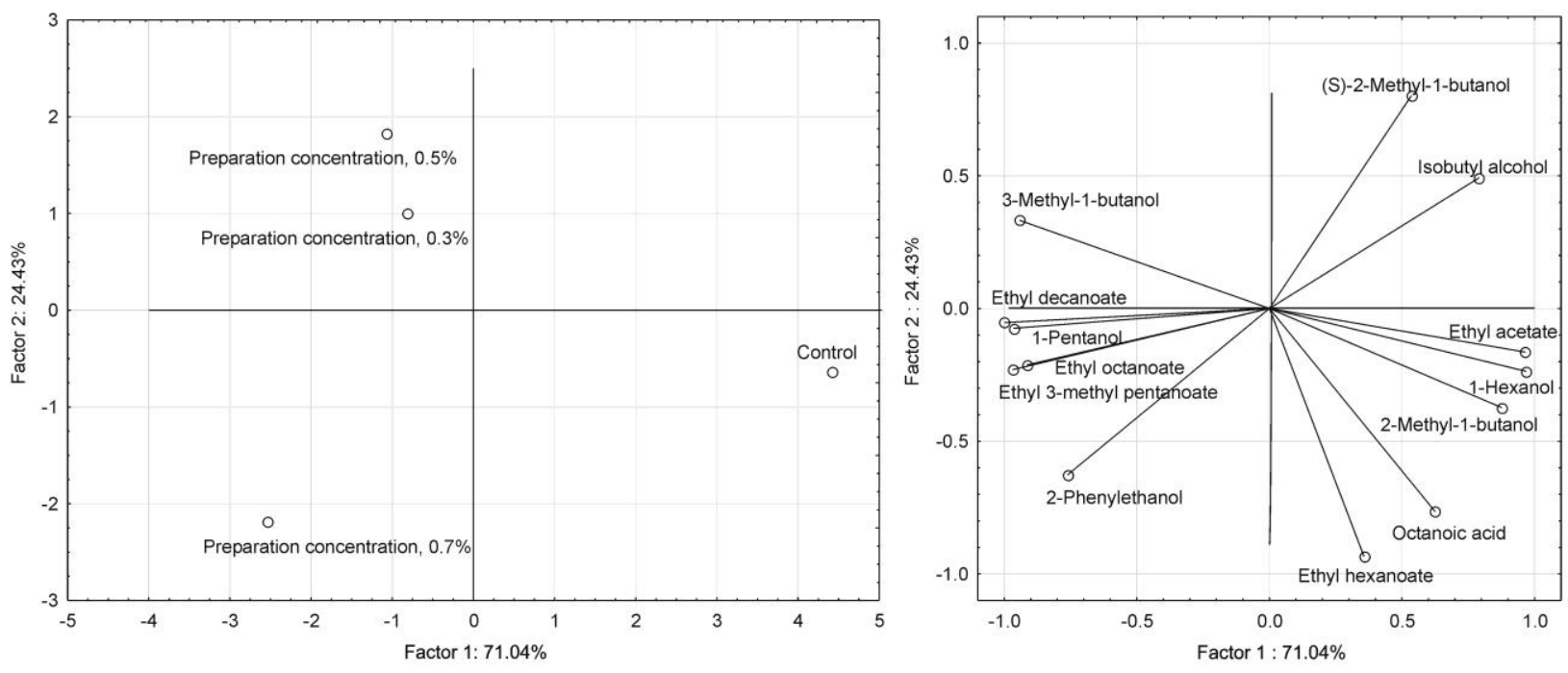

FIGURE 2

Principal component analysis of the relative chromatographic areas (considering only the volatile compounds with a relative peak area higher than $1 \%$ of the volatile organic compounds identified in the Prokupac wines obtained from control grapes and grapes treated with different concentrations of $B$. subtilis Ch-13 preparation

produced Prokupac wines. PCA explained more than $90 \%$ of the total variability among wine samples (Fig. 2), while the first principal component (PC1) explained more than $70 \%$ of the total variability.

PCA showed a clear differentiation between the control wine sample and the wine samples produced from the treated grapes. It was observed that the wines samples produced from the grapes treated with $B$. subtilis Ch-13 preparations showed strong and positive correlations with the ethyl ethers, while the wine produced from the control grape sample showed a strong correlation with 2-methyl-1-butanol and ethyl acetate, which are responsible for sweet and floral aromas. However, it was observed that the wines produced from the grapes treated with higher preparation concentrations $(0.5 \%$ and $0.7 \%$ ) were grouped in the negative quadrant of $\mathrm{PC} 2$, which indicates that higher $B$. subtilis Ch-13 preparation concentrations resulted in wines with more 3-methyl-1butanol and ethyl dodecanoate, which are responsible for floral and fruity aromas.

\section{CONCLUSIONS}

To date, agricultural producers have become accustomed to using agrochemicals to protect crops and enhance yields. This has had unintended consequences on human health and the environment. Finding an alternative to hazardous agrochemicals has become a major focus in modern agriculture. Microbial-based preparations are natural pesticides that have great potential to replace agrochemicals because they are not harmful for either the environment or the plant. In contrast, they can even promote plant growth and enhance fruit quality. This knowledge is especially important in viticulture because of the susceptibility of grapes to disease attacks in the pre-harvest period, when agrochemicals cannot be applied due to withholding periods.
The application of microbiological preparations is an ideal alternative because, in addition to having a biofungicidal effect and protecting the grapes, they have the effect of improving grape quality. This represents great potential for improving wines quality, especially wines prepared from grape varieties with certain undesirable properties that are sure to affect the final product's characteristics. In particular, the Prokupac grape, studied in this work, is a grape variety that typically gives wines with lower colour intensity, which can be perceived negatively by consumers because of the prejudice that wines that are not intensely coloured are not of superior quality.

In this paper, we have shown that the application of microbiological preparation based on B. subtilis Ch-13 to the grapes in the pre-harvest period significantly improves the coloration of wines made from the treated grapes. So, these research findings can be considered very valuable, especially for the production of quality wines from poorly coloured grape varieties. In addition, the results of our study show that $B$. subtilis Ch-13 positively influences the sugar content of grapes, which could be useful for northern and cool climatic regions or for varieties in which an insufficient sugar level in the grapes is a common occurrence. Also, the application of this preparation can improve the accumulation of polyphenolic compounds in grapes and wine, and increase the content of higher alcohols and esters, which are all responsible for the sensorial characteristics of the wine. Since the content of polyphenolic compounds has thus far been associated with the grape cultivar and environmental and climatic conditions, it is valuable to know that viticultural practices, such as the application of microbiological preparation, could promote the accumulation of these classes of compounds. The established potential of particular microbiological preparations represents valuable 
information for grape and wine producers, and it should also serve as a stimulus for further research in this field.

\section{LITERATURE CITED}

Abbey, J.A., Percival, D., Abbey, L., Asiedu, S.K., Prithiviraj, B. \& Schilder, A., 2019. Biofungicides as alternative to synthetic fungicide control of grey mould (Botrytis cinerea) - prospects and challenges. Biocontrol Sci. Technol. 29(3), 241-262.

Alori, E.T. \& Babalola, O.O., 2018. Microbial inoculants for improving crop quality and human health in Africa. Front. Microbiol. 9, 2213 doi: 10.3389/fmicb.2018.02213.

Aoki, T., Aoki, Y., Ishiai, S., Otoguro, M. \& Suzuki, S., 2017. Impact of Bacillus cereus NRKT on grape ripe rot disease through resveratrol synthesis in berry skin. Pest Manag. Sci. 73(1), 174-180.

Babincev, L.M., Gurešić, D.M. \& Simonović, R.M., 2016. Spectrophotometric characterization of red wine color from the vineyard region of Metohia. J. Agric. Sci. 61(3), 281-290.

Biarnès, A., Bailly, J.S. \& Boissieux, Y., 2009. Identifying indicators of the spatial variation of agricultural practices by a tree partitioning method: The case of weed control practices in a vine growing catchment. Agric. Syst. 99(2-3), 105-116.

Bleve, G., Tufariello, M., Vetrano, C., Mita, G. \& Grieco, F., 2016. Simultaneous alcoholic and malolactic fermentations by Saccharomyces cerevisiae and Oenococcus oeni cells co-immobilized in alginate beads. Front. Microbiol. 7, 943 doi: 10.3389/fmicb.2016.00943

Bogicevic, M., Maras, V., Mugoša, M., Kodžulović, V., Raičević, J., Šućur, S. \& Failla, O., 2015. The effects of early leaf removal and cluster thinning treatments on berry growth and grape composition in cultivars Vranac and Cabernet Sauvignon. Chem. Biol. Technol. Agric. 2(1), 13 doi: 10.1186/ s40538-015-0037-1

Calvo-Garrido, C., Roudet, J., Aveline, N., Davidou, L., Dupin, S. \& Fermaud, M., 2019. Microbial antagonism toward botrytis bunch rot of grapes in multiple field tests using one Bacillus ginsengihumi strain and formulated biological control products. Front. Plant Sci. 10, 15 https://doi. org/10.3389/fpls.2019.00105

Castilhos, M.B.M., de Cattelan, M.G., Conti-Silva, A.C. \& Del Bianchi, V.L., 2013. Influence of two different vinification procedures on the physicochemical and sensory properties of Brazilian non-Vitis vinifera red wines. LWT - Food Sci. Technol. 54(2), 360-366.

Chambers IV, E. \& Koppel, K., 2013. Associations of volatile compounds with sensory aroma and flavor: The complex nature of flavor. Molecules $18(5), 4887-4905$.

Chebotar, V.K., Makarova, N.M., Shaposhnikov, A.I. \& Kravchenko, L.V., 2009. Antifungal and phytostimulating characteristics of Bacillus subtilis Ch-13 rhizospheric strain. Prikl. Biokhim. Mikrobiol. 45(4), 465-469.

Coradini, R., Madoşă, E., Irina, P. \& Cristina, C., 2014. Change of hue and intensity of color during the fermentation in case of must obtained from various varieties of red grapes from Minis-Maderat Winery. J. Hort. For. Biotechnol. 18(4), 55-62.

Cosme, F., Gonçalves, B., Bacelar, E.A., Ines, A., Jordão, A.M. \& Vilela, A., 2017. Genotype, environment and management practices on red/darkcolored fruits phenolic composition and its impact on sensory attributes and potential health benefits. In: Soto-Hernández, M. (ed). Phenolic compounds - Natural sources, importance and applications. InTech, London, UK. pp. 261-281.

Damalas, C.A. \& Koutroubas, S.D., 2018. Current status and recent developments in biopesticide use. Agric. 8(1), 13 doi:10.3390/ agriculture 8010013
De-la-Fuente-Blanco, A., Sáenz-Navajas, M.P. \& Ferreira, V., 2016. On the effects of higher alcohols on red wine aroma. Food Chem. 210, 107-114.

Escribano-Viana, R., López-Alfaro, I., López, R., Santamaría, P., Gutiérrez, A.R. \& González-Arenzana, L., 2018. Impact of chemical and biological fungicides applied to grapevine on grape biofilm, must, and wine microbial diversity. Front. Microbiol. 9, 59 doi: 10.3389/fmicb.2018.00059.

Esteban, M., Villanueva, M. \& Lissarrague, J., 2002. Relationships between different berry components in Tempranillo (Vitis vinifera $\mathrm{L}$ ) grapes from irrigated and non-irrigated vines during ripening. J. Sci. Food Agric. 82(10), 1136-1146.

González-Rodríguez, J., Pérez-Juan, P. \& Luque de Castro, M.D., 2002. Method for the simultaneous determination of total polyphenol and anthocyan indexes in red wines using a flow injection approach. Talanta $56,53-59$.

Guerrero, R.F., Cantos-Villar, E., Ruiz-Moreno, M.J., Puertas, B., Cuevas, F.J. \& Moreno-Rojas, J.M., 2019. Influence of vertical training systems on warm climate red winemaking: Wine parameters, polyphenols, volatile composition, and sensory analysis. Oeno One 53(3), 471-486.

Jackson, R.S., 2008. Wine science: Principles and applications. Elsevier, London, UK.

Jordão, A., Vilela, A. \& Cosme, F., 2015. From sugar of grape to alcohol of wine: Sensorial impact of alcohol in wine. Beverages 1(4), 292-310.

Kim, B.S. \& Hwang, B.K., 2007. Microbial fungicides in the control of plant diseases. J. Phytopathol. 155(11-12), 641-653.

Lakićević, S., Popović, T., Matijašević, S., Ćirković, B., Lazić, M. \& Popović-Đorđević, J., 2019. Chemical evaluation of autochthonous variety "Prokupac" red wine with the addition of selected aromatic herbs. Ann. Univ. Craiova - Agric. Mont. Cadastre Ser. 49(1), 87-97.

Lakićević, S.H., Popović Djordjević, J.B., Pejin, B., Djordjević, A.S., Matijašević, S.M. \& Lazić, M.L., 2018. An insight into chemical composition and bioactivity of "Prokupac" red wine. Nat. Prod. Res. 34(11), 1542-1546 doi:10.1080/14786419.2018.1516219

Lambrechts, M.G. \& Pretorius, I.S., 2000. Yeast and its importance to wine aroma - A review. S. Afr. J. Enol. Vitic. 21(1), 97-129.

Malićanin, M., Rac, V. \& Rakić, V., 2017. The effect of inactivated yeastbased products on the process of wine aging, phenolic compounds and sensory characteristics of red wine Prokupac. BIO Web Conf. 9, 02004.

Marković, N., Pržić, Z., Rakonjac, V., Todić, S., Ranković-Vasić, Z., Matijašević, S. \& Bešlić, Z., 2017. Ampelographic characterization of Vitis cv "Prokupac" clones by multivariate analysis. Rom. Biotechnol. Lett. 22(5), 12868-12875.

McKay, M. \& Buica, A., 2020. Factors influencing olfactory perception of selected off-flavour-causing compounds in red wine - A review. S. Afr. J. Enol. Vitic. 41(1), 56-71.

Mozell, M.R. \& Thachn, L., 2014. The impact of climate change on the global wine industry: Challenges \& solutions. Wine Econ. Policy 3(2014), 81-89.

Nedelkovski, D., Cvetković, J., Beleski, K. \& Poposka, H., 2017. Phenolic composition of Vranec grapevine cultivar (Vitis vinifera L.) grafted on different rootstock. Bulg. J. Agric. Sci. 23(3), 389-395.

Niculescu, V.C., Paun, N. \& Ionete, R.E., 2018. The evolution of polyphenols from grapes to wines. In: Jordão, A.M. (ed). Grapes and wines - Advances in production, processing, analysis and valorization. InTech, London, UK. pp. 119-141.

OIV., 2019. Compendium of international methods of wine and must analysis. OIV, Paris. 
Otoguro, M. \& Suzuki, S., 2018. Status and future of disease protection and grape berry quality alteration by micro-organisms in viticulture. Lett. Appl. Microbiol. 67(2), 106-112.

Pagliarini, E., Laureati, M. \& Gaeta, D., 2013. Sensory descriptors, hedonic perception and consumer's attitudes to Sangiovese red wine deriving from organically and conventionally grown grapes. Front. Psychol. 4, 896 doi: 10.3389/fpsyg.2013.00896

Pertot, I., Caffi, T., Rossi, V., Mugnai, L., Hoffmann, C., Grando, M.S., Gary, C., Lafond, D., Duso, C., Thiery, D., Mazzoni, V. \& Anfora, G., 2017. A critical review of plant protection tools for reducing pesticide use on grapevine and new perspectives for the implementation of IPM in viticulture. Crop Prot. 97, 70-84.

Pineau, B., Barbe, J.C., Van Leeuwen, C. \& Dubourdieu, D., 2009. Examples of perceptive interactions involved in specific "Red-" and "Black-berry" aromas in red wines. J. Agric. Food Chem. 57(9), 3702-3708.

Raicevic, V., Sivcev, B., Jakovljevic, M., Antic, S. \& Lalevic, B., 2004. The influence of the biofertilizer type on wine quality and soil microbiological activity. Proc. 1st Intern. Symp. Grapevine Growing, Commerce and Research, June 2004, Lisbon, Portugal.

Rolli, E., Marasco, R., Saderi, S., Corretto, E., Mapelli, F., Cherif, A., Borin, S., Valenti, L., Sorlini, C. \& Daffonchio, D., 2017. Root-associated bacteria promote grapevine growth: From the laboratory to the field. Plant Soil 410(1-2), 369-382.

Shafi, J., Tian, H. \& Ji, M., 2017. Bacillus species as versatile weapons for plant pathogens: A review. Biotechnol. Biotechnol. Equip. 31(3), 446-459.

Shi, P., Song, C., Chen, H., Duan, B., Zhang, Z. \& Meng, J., 2018. Foliar applications of iron promote flavonoids accumulation in grape berry of Vitis vinifera $\mathrm{cv}$. Merlot grown in the iron deficiency soil. Food Chem. 253, 164 170 .

Sivčev, B., Jović, S., Raičević, V., Petrović, A. \& Lalević, B., 2005. Application of microbiological fertilizers in viticulture: Grape yield and quality of wine cv. Riesling. J. Agric. Sci. 50(1), 19-26.
Stamenković, S., Beškoski, V., Karabegović, I., Lazić, M. \& Nikolić, N., 2018. Microbial fertilizers: A comprehensive review of current findings and future perspectives. Spanish J. Agric. Res. 16(1), e09R01.

Tangolar, S., Alkan Torun, A., Tarım, G., Ada, M., Aydın, O., Kaçmaz, S. \& Tangolar, S., 2019. The effect of microbial fertilizer applications on grape yield, quality and mineral nutrition of some early table grape varieties. Selcuk J. Agric. Food Sci. 33(2), 62-66.

Thiollet-Scholtus, M., Caillé, S., Samson, A., Lambert, J.J. \& Morlat, R., 2014. Use of production practices and sensory attributes to characterize Loire Valley red wines. Am. J. Enol. Vitic. 65(1), 50-58.

Vilanova, M., Genisheva, Z., Masa, A. \& Oliveira, J.M., 2010. Correlation between volatile composition and sensory properties in Spanish Albariño wines. Microchem. J. 95(2), 240-246.

Vilela, A., Schuller, D., Mendes-Faia, A. \& Côrte-Real, M., 2013. Reduction of volatile acidity of acidic wines by immobilized Saccharomyces cerevisiae cells. Appl. Microbiol. Biotechnol. 97(11), 4991-5000.

Welke, J.E., Zanus, M., Lazzarotto, M. \& Alcaraz Zini, C., 2014. Quantitative analysis of headspace volatile compounds using comprehensive twodimensional gas chromatography and their contribution to the aroma of Chardonnay wine. Food Res. Int. 59, 85-99.

Yadav, S.S., Redden, R.J., Hatfield, J.L., Lotze-Campen, H. \& Hall, A.J.W., 2011. Crop adaptation to climate change. John Wiley \& Sons, Inc., UK.

Yildirim, E., Karlidag, H., Turan, M., Dursun, A. \& Goktepe, F. 2011. Promotion of Broccoli by Plant Growth Promoting Rhizobacteria. Hort. Sci. 46(6), 932-936.

Yilmaztekin, M., 2014. Characterization of potent aroma compounds of cape gooseberry (Physalis peruviana L.) fruits grown in Antalya through the determination of odor activity values. Int. J. Food Prop. 17(3), 469-480.

Zheng, Y., Tian, L., Liu, H., Pan, Q., Zhan, J. \& Huang, W., 2009. Sugars induce anthocyanin accumulation and flavanone 3-hydroxylase expression in grape berries. Plant Growth Regul. 58(3), 251-260.

Zhu, F., Du, B. \& Li, J., 2016. Aroma compounds in wine. In: Morata, A. (ed.). Grape and wine biotechnology. InTech, London, UK. pp. 273-283. 